\title{
ЛИТЕЙНЫЕ И МЕТАЛЛУРГИЧЕСКИЕ ПРОЦЕССЫ
}

УДК 621.74

DOI: $10.35211 / 1990-5297-2020-7-242-41-45$

\author{
И. О. Леушин, А. Н. Грачев, В. Н. Назаров, П. А. Горохов \\ ВОЗМОЖНОСТИ ПОЛУЧЕНИЯ ОТЛИВОК ИЗ ПЕНОАЛЮМИНИЯ \\ С ПРИМЕНЕНИЕМ ГРАНУЛ «СУХОГО ЛЬДА»
}

Нижегородский государственный технический университет им. Р. Е. Алексеева

e-mail: igoleu@yandex.ru, alexgra76@mail.ru,nazarovvn@rambler.ru,pavel_goroxov@mail.ru

Представлены результаты проведенного авторами аналитического обзора современных способов получения пеноалюминия и литых заготовок из этого материала. Приводятся примеры пено- и порообразователей, используемых в российском производстве пеноалюминия. Показано, что основной проблемой производства литых изделий из пеноалюминия является нестабильность их качества, обусловленная разнородностью и неравномерностью распределения пор в теле отливки, приводящих к тому, что каждая последующая отливка в серии будет иметь идентичные прочностные свойства, массу и плотность. Выполнен сравнительный анализ вариантов изготовления литых изделий из пеноалюминия, предусматривающих ввод пено- и порообразователя в алюминиевый расплав с последующим перемешиванием до заливки в литейную форму и непосредственно в ее рабочую полость.

Предлагается технологическая схема, предусматривающая ввод пено- и порообразователя в виде гранул «сухого льда»в алюминиевый расплав непосредственно в рабочей полости литейной формы. Она позволяет получать как пеноалюминиевые плиты для последующей механической обработки, так и сложные фасонные отливки, габаритные размеры которых ограничиваются лишь способностью формы удерживать давление при сублимации $\mathrm{CO}_{2}$. Главными преимуществами предлагаемой схемы перед известными являются малозатратность и простота практической реализации. По мнению авторов, эффективная практическая реализация данной схемы вполне возможна на участках кокильного литья действующих литейных цехов машиностроительных предприятий.

Ключевые слова: пеноалюминий, сухой лед, гранула, сублимация, отливка, ресурсосберегающая технология.

\section{O. Leushin, A. N. Grachev, V. N. Nazarov, P. A. Gorokhov \\ POSSIBILITIES OF OBTAINING CASTINGS FROM ALUMINUM FOAM WITH THE USE OF "DRY ICE" GRANULES}

\section{Federal state budgetary educational institution of higher education «n.a. R. E. Alekseev Nizhny Novgorod State Technical University»}

The results of the authors ' analytical review of modern methods for obtaining foamed aluminum and cast blanks from this material are presented. Measurements of foam-and foam-forming agents used in the Russian production of foamed aluminum are given. It is shown that the main problem in the production of cast products made of aluminum foam is the instability of their quality, due to the heterogeneity and uneven distribution of pores in the casting body, which leads to the fact that each subsequent casting in the series will have identical strength properties, mass and density. A comparative analysis of options for manufacturing cast products made of aluminum foam, which provide for the introduction of foam and poroobrazovatel in the aluminum melt, followed by mixing before pouring into the mold and directly into its working cavity.

A technological scheme is proposed that provides for the introduction of a foam and foam-forming agent in the form of "dry ice" granules into the aluminum melt directly in the working cavity of the mold. It allows you to obtain both foamed aluminum plates for subsequent machining, and complex shaped castings, the dimensions of which are limited only by the ability of the mold to hold pressure during CO2 sublimation. The main advantages of the proposed scheme over the known ones are low cost and ease of practical implementation. According to the authors, effective practical implementation of this scheme is quite possible in the areas of coking casting of existing foundries of machine-building enterprises.

Keywords: foam aluminum, dry ice, granule, sublimation, casting, resource-saving technology.

(С Леушин И. О., Грачев А. Н., Назаров В. Н., Горохов П. А., 2020 
В алюминиевом литье нередко встречаются проблемы с дефектами отливок, которые имеют газовое происхождение, однако именно они в свое время послужили толчком к созданию легких и прочных пеноалюминиевых конструкций с упорядоченной ячеистой структурой.

В качестве основы пеноалюминия используют технический $\mathrm{Al}, \mathrm{Mg}, \mathrm{Al}<11 \% \mathrm{Si}$ (технические (нелегированные) сплавы, содержание посторонних примесей в которых составляет не более $1 \%$ ). Пеноалюминий представляет собой легкий (с плотностью $\gamma=0,2-0,9$ г/ $\mathrm{cm}^{3}$, менее, чем у воды) сравнительно прочный материал из алюминия с ячеистой структурой, полученной введением в Al-расплав порообразных веществ, преимущественно гидридов $\mathrm{Ti}, \mathrm{Zr}, \mathrm{Ba}, \mathrm{Li}$, а также $\mathrm{CaCO}_{3}$, которые, разлагаясь, вспенивают металл и заполняют металлические ячейки газом (в случае введения гидридов - водородом, кар- боната кальция - диоксидом углерода). Из этого материала, который может иметь закрытые или открытые $n o p b$, производят слитки круглого или прямоугольного сечения, полосы, а также фасонные заготовки. Пеноалюминий с закрытыми порами применяют как конструкционный материал в судо- и машиностроении, строительстве и других отраслях техники [1].

Пена - это тонкодисперсное проникновение воздуха в твердотельные вещества или жидкости. Ее образование происходит при помощи веществ-пенообразователей, способствующих образованию устойчивой пены, а также веществ-порообразователей, используемых в производстве пористых материалов для создания в них системы соединенных пор-каналов или изолированных пор-ячеек.

Примеры пено- и порообразователей представлены в приведенной ниже таблице.

Примеры пено- и порообразователей [2]

\begin{tabular}{|c|c|c|}
\hline Вещество & Основные характеристики & $\begin{array}{l}\text { Механизм формирования пор } \\
\text { в пеноалюминии }\end{array}$ \\
\hline $\begin{array}{l}\text { 1. Гидрид ти- } \\
\text { тана }\left(\mathrm{TiH}_{2}\right)\end{array}$ & $\begin{array}{l}\text { Негигроскопичен и устойчив по отношению к разбавлен- } \\
\text { ным кислотам. Разложение гидрида титана начинается } \\
\text { при температуре } 300 \text { } \mathrm{C} \text {, но дегидрирование даже при } \\
\text { температуре } 1100{ }^{\circ} \mathrm{C} \text { не приводит к полному удалению } \\
\text { водорода из титана. Используется как порообразователь } \\
\text { для изготовления пенометаллов; как источник чистого } \\
\text { водорода; как катализатор в реакциях гидрирования ор- } \\
\text { ганических соединений [3] }\end{array}$ & \multirow{3}{*}{$\begin{array}{l}\text { При перегреве химических компонен- } \\
\text { тов выше температуры ликвидус алю- } \\
\text { миниевого сплава происходит разло- } \\
\text { жение на водород и углекислый газ в } \\
\text { разных случаях, после чего алюминие- } \\
\text { вый расплав насыщается газами }\end{array}$} \\
\hline $\begin{array}{l}\text { 2. Бикарбонат } \\
\text { натрия } \\
\left(\mathrm{NaHCO}_{3}\right)\end{array}$ & $\begin{array}{l}\text { Кислая натриевая соль угольной кислоты. Проявляет все } \\
\text { свойства соли сильного основания и слабой кислоты. } \\
\text { В водных растворах имеет слабощелочную реакцию. В } \\
\text { широком диапазоне концентраций в водном раство- } \\
\text { ре } p H \text { раствора изменяется незначительно, на этом осно- } \\
\text { вано применение раствора вещества в качестве буферно- } \\
\text { го раствора }\end{array}$ & \\
\hline $\begin{array}{l}\text { 3. Карбонат } \\
\text { кальция } \\
\left(\mathrm{CaCO}_{3}\right)\end{array}$ & $\begin{array}{l}\text { Карбонат кальция в обычных условиях представляет со- } \\
\text { бой вещество белого цвета, которое при прокаливании } \\
\text { разлагается, однако плавится без разложения (условие - } \\
\text { избыточное давление } \mathrm{CO}_{2} \text { ) }\end{array}$ & \\
\hline $\begin{array}{l}\text { 4. Хлорид } \\
\text { кальция } \\
\left(\mathrm{CaCl}_{2}\right)\end{array}$ & $\begin{array}{l}\text { Твердое вещество белого цвета. Кристаллы, имеющие } \\
\text { кубическую форму, обладают высокой гигроскопично- } \\
\text { стью и быстро поглощают влагу из окружающего возду- } \\
\text { ха. Хорошо растворим в низших спиртах и органических } \\
\text { растворителях }\end{array}$ & \multirow{4}{*}{$\begin{array}{l}\text { Происходит заливка алюминиевого } \\
\text { расплава в форму с заполнением по- } \\
\text { лостей между гранулами водораство- } \\
\text { римых солей расплавом, после затвер- } \\
\text { девания алюминиевого расплава изде- } \\
\text { лие извлекают из формы и помещают } \\
\text { в воду для растворения соли и образо- } \\
\text { вания пор }\end{array}$} \\
\hline $\begin{array}{l}\text { 5. Хлорид ба- } \\
\text { рия }\left(\mathrm{BaCl}_{2}\right)\end{array}$ & $\begin{array}{l}\text { При нагревании } \mathrm{BaCl}_{2} \text { разлагается с выделением химиче- } \\
\text { ски активногохлороводорода }\end{array}$ & \\
\hline $\begin{array}{l}\text { 6. Бромид } \\
\text { кальция }\left(\mathrm{CaBr}_{2}\right)\end{array}$ & $\begin{array}{l}\text { Бромид кальция используется как дегидратирующий } \\
\text { агент, катализатор }\end{array}$ & \\
\hline $\begin{array}{l}\text { 7. Йодид } \\
\text { кальция }\left(\mathrm{CaJ}_{2}\right)\end{array}$ & $\begin{array}{l}\text { Бесцветное гигроскопичное твердое вещество; представ- } \\
\text { ляет собой соль, которая весьма растворима в воде, реа- } \\
\text { гирует с кислородом и диоксидом углерода в воздухе }\end{array}$ & \\
\hline
\end{tabular}

В производстве пористых изделий из металлов и сплавов чаще всего пено- и порообра- зователи вводят в расплавленную металлическую матрицу как необходимые технологиче- 
ские добавки, а затем удаляемые из монолитной заготовки различными способами, например, выжиганием, выплавлением, растворением и т. П. [4].

Эти добавки в совокупности с условиями охлаждения и другими параметрами технологического процесса производства литья не только определяют размер образующихся пор, но и оказывают существенное влияние на вязкость, жидкотекучесть и относительную плотность металлического расплава, и, в конечном итоге, на качество конечного изделия из пеноалюминия [5].

Традиционно основной проблемой производства литых изделий из пеноалюминия считается нестабильность их качества, обусловленная разнородностью и неравномерностью распределения пор в теле отливки, приводящих к тому, что каждая последующая отливка в серии будет иметь идентичные прочностные свойства, массу и плотность.

Принципиально принято различать варианты изготовления литых изделий из пеноалюминия, предусматривающие ввод пено- и порообразователя в алюминиевый расплав с последующим перемешиванием либо до заливки в литейную форму, либо непосредственно в ее рабочей полости. Оба они имеют свои преимущества и недостатки.

Первый вариант имеет преимущества в получении пеноалюминия непрерывным литьем и вытягиванием слитка со скоростью, обеспечивающей затвердевание расплава на основе алюминия с введенным в него химическим соединением, которое при нагревании разлагается, выделяя газ $\mathrm{CO}_{2}$ до начала активного разложения для изготовления листов и полос. Недостатком является то, что для формирования плотной заготовки с конфигурацией готового изделия следует поместить плотную заготовку в форму и осуществлять высокотемпературную термообработку для вспенивания, а это является достаточно энергоемким и многостадийным технологическим процессом.

Второй вариант имеет такие достоинства, как уменьшение стадий технологического процесса; отсутствует использование оборудования для смешивания газифицирующих агентов вне рабочей полости литейной формы. Недостатком в некоторых случаях является неоднородность пор в готовом изделии из пеноалюминия.

В данной статье рассматривается технологическая схема производства литых изделий из пеноалюминия по второму варианту - варианту внутриформенного ввода пено- и порообразователя в алюминиевый расплав.

Известны способы его реализации с использованием в качестве пено- и порообразователя гранул полимера или водорастворимых солей.

Так, например, способ [5] включает в себя смешивание в литейной форме песчано-глинистой смеси и гранул полимера с последующим выжиганием частичек полимера и наполнение литейной формы расплавленным металлом, подаваемым в нее под давлением.

Очевидно, и это является недостатком способа, выжигание гранул полимера из металлической основы требует существенных энергозатрат.

Способ [6] предусматривает использование таких порообразователей как, гидрид титана $\left(\mathrm{TiH}_{2}\right)$, бикарбонат натрия $\left(\mathrm{NaHCO}_{3}\right)$ или карбонат кальция $\left(\mathrm{CaCO}_{3}\right)$ в количестве от 0,5 до $1 \%$ от общей массы - объемные частицы кальция и титана, добавленные в расплав, в конечном счете определяют относительную плотность изделия. При этом размер пор может варьироваться от 0,5 до 5 мм в зависимости от содержания порообразователя и условий охлаждения.

Практический интерес представляет способ получения пеноалюминия [7], при котором приготавливают алюминиевый расплав, перегретый выше линии ликвидуса, отличается тем, что расплав заливают в форму, нагретую до той же температуры, предварительно заполненную гранулами водорастворимых солей (бромид или йодид кальция, или бария), химически не взаимодействующих с алюминиевым расплавом, имеющих температуру плавления выше температуры нагрева расплава и формы и плотность выше плотности алюминиевого расплава, а после затвердевания литую заготовку извлекают из формы и помещают в воду. Соль растворяется в воде, образуя поры необходимого размера, соответствующие дисперсности солевых гранул.

Однако и эти способы не свободны от недостатков. В частности, для их практической реализации помимо дорогостоящих водорастворимых солей необходимо применение специального оборудования.

Представляемая работа ориентирована на поиск альтернативного малозатратного способа получения отливок из пеноалюминия, характеризующегося простотой практической реализации.

Для этого авторами данной статьи предлагается взять за основу вариант внутриформенного ввода пено- и порообразователя в алюми- 
ниевый расплав, а в качестве пено- и порообразователя применить гранулы «сухого льда».

«Сухой лед» представляет собой белую снегообразную массу, твердотельный вариант диоксида углерода, который испытывает сублимацию (переходит в газообразное состояние) при температуре $-78{ }^{\circ} \mathrm{C}[8]$. Вещество изготавливается в промышленных масштабах согласно ГОСТ 12162-77.

Физическая сущность предлагаемого решения заключается в контролируемом образова- нии газожидкометаллической смеси, где матрицей выступает алюминиевый расплав, а дисперсной средой-порообразователем - углекислый газ как результат высокотемпературной сублимации гранул «сухого льда», и дальнейшем управляемом формировании газотвердометаллического изделия заданной геометрической формы.

Принципиальная схема предлагаемого способа получения отливки из пеноалюминия представлена на приведенном ниже рисунке.

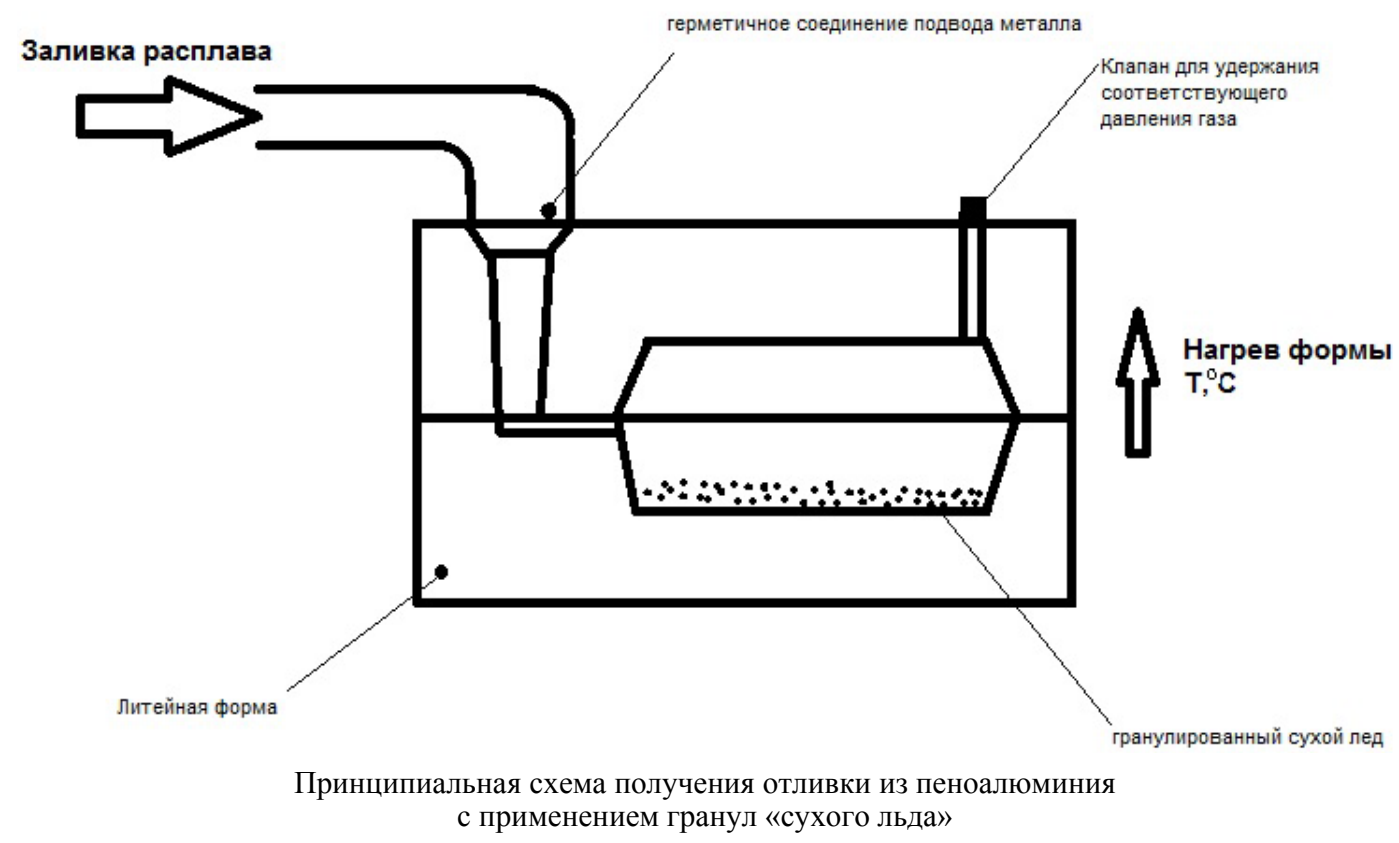

В окрашенную рабочую полость предварительно нагретой металлической литейной формы засыпается расчетное количество «сухого льда» в виде гранул определенного размера, обеспечивающее соответствие времени сублимации гранул и длительности затвердевания конкретной отливки. После герметизации формы, необходимой для предотвращения утечки газа-порообразователя в атмосферу цеха, происходит ее заливка расплавом и, как следствие, создание избыточного газового давления. При температуре начала затвердевания расплава открывается соответствующий клапан, что позволяет снизить давление газа в полости литейной формы до атмосферного, вывести часть газа в газоочистную установку и обеспечить интенсификацию формирования пор в алюминиевой матрице.

Для контроля размера пор в ячеистой структуре пеноалюминия предлагается регулировка режима открытия клапана, что направлено на повышение управляемости процесса.
По мнению авторов данной статьи, практическая реализация данной схемы вполне возможна на участках кокильного литья действующих литейных цехов машиностроительных предприятий.

Предлагаемый способ позволяет получать как пеноалюминиевые плиты для последующей механической обработки, так и сложные фасонные отливки, габаритные размеры которых ограничиваются лишь способностью формы удерживать давление при сублимации $\mathrm{CO}_{2}$. Главными преимуществами предлагаемого способа перед известными являются малозатратность и простота практической реализации.

При этом становится реальным обеспечить такие технические показатели литого изделия из пеноалюминия, как:

- разнородность структуры отливки (размер ячеистой структуры пор в объеме отливки) не более $10 \%$;

- диапазон колебаний массы отливки в пределах от 3 до $5 \%$; 
- прогнозируемая плотность отливки, соответствующая заданным требованиям, установленным конструктором.

\section{БИБЛИОГРАФИЧЕСКИЙ СПИСОК}

1. Энциклопедический словарь по металлургии / гл. ред. Н. П. Лякишев. - М. : Интермет Инжиниринг, 2000.

2. Свойства органических соединений. Справочник // под ред. А. А. Потехина. - Л. : Химия, 1984. - 520 с.

3. Порошковая металлургия титана / В. С. Устинов, Ю. Г. Олесов, Л. Н. Антипин, В. А. Дрозденко. - Металлургия, 1973. - С. 28-70.

4. Калиниченко, В. А. Вспененные пористые теплоизоляционные материалы на основе алюминия / В. А. Ка- линиченко, А. А. Андрушевич // Литье и металлургия. 2012. - № 3. - C. 31-34.

5. Бутарович, Д. О. Пеноалюминий как энергопоглощающий материал и его основные свойства / Д. О. Бутарович, А. А. Смирнов, Д. М. Рябов // Машиностроение. 2011. - № 7. - С. 53-58.

6. Ковтунов А. И., Чермашенцева Т. В., Семистенов Д. А., Сидоров В. П. Способ получения пеноалюминия : патент РФ № 2400552; опубл. 10.06.2010; бюл. № 27.

7. Ковтунов А. И., Хохлов Ю. Ю. Способ формирования пеноалюминия : патент РФ № 2492257; опубл. 10.09.2013; бюл. № 25.

8. Раков, Э. Г. Углерода диоксид (рус.) / Э. Г. Раков // Большая российская энциклопедия. - М. : Большая российская энциклопедия, 2016. - Т. 32. - С. 662-663. 